\title{
Aboriginal and Torres Strait Islander mental health: paradise lost?
}

\section{Broader thinking is needed to restore mental health in a vulnerable population}

t may well be that Australian Aboriginal culture, before significant European contact, provided conditions for mental health that the rest of the world would envy. Traditional Aboriginal culture has several factors that strongly reinforce good mental health. Sense of self was seen as being intimately connected to all aspects of life, community, spirituality, culture and country. Material needs were provided for through sharing rules, and relationships and kinship defined social roles.

Aboriginal people derived a sense of meaning and understanding of life experience from their connection to country and their Dreaming. Spiritual beliefs offered guidance, comfort, and a sense of connectivity and belonging. Lore, the body of knowledge that defined their culture, and the Elders who contained and interpreted the Lore, were highly valued. Over 200 traditional languages and other methods of communication allowed rich expression, and formal ceremony allowed a method of dealing with life's transitions through birth, initiation and death.

Men and women had defined economic and cultural roles, and children had a range of "aunties" and older siblings to take over child care if a mother was stressed. ${ }^{1}$
Torres Strait Islander culture also had rituals and societal mechanisms that appeared to reinforce mental health. ${ }^{1}$

Early reports of Aboriginal and Torres Strait Islander people mention occasions of mental illness, but these were considered to be rare events. ${ }^{2}$ This is in marked comparison to the high rates of mental illness described by Hunter and colleagues ${ }^{3}$ and Jorm and colleagues ${ }^{4}$ in this issue of the Journal. Hunter and colleagues identified rates and correlates of psychosis in a defined Aboriginal and Torres Strait Islander population in Far North Queensland, while Jorm and colleagues identified broader issues with respect to the mental health of Aboriginal and Torres Strait people by reviewing community studies.

Jorm and co-workers point to the difficulty of establishing validity in community surveys through the use of formal diagnostic instruments, underscoring concerns about the validity of Western psychiatric diagnoses for non-Western cultural groups. Such concerns include the standards of what constitutes scientific evidence, the meaning and uses of ethnic and racial categories, interpretations of differences of prevalence rates for mental disorders and the tension between universal and group-specific approaches to mental health research and policy. ${ }^{5}$ Else-
Robert M Parker BA(Hons), BMed, FRANZCP, Adjunct Associate Professor of Psychiatry

Northern Territory Clinical School, James Cook University, Townsville, QLD.

robert.parker@ nt.gov.au

doi: 10.5694/mjall.11561

Clinical focus $p 118$ Research p 133 
where, Hunter noted that "Indigenous societies have undergone rapid social change and it should be no surprise that there have been changing patterns of mental health problems including mental health disorders". ${ }^{6} \mathrm{He}$ added that "a constant across most of the above considerations ... is a change, both in the patterns of disorders for social and emotional well being and in the social context in which these disorders arise" ${ }^{\prime}{ }^{6}$

To an extent, these difficulties may be overcome through the use of high-quality small surveys like the Western Australian Aboriginal Child Health Survey, ${ }^{7}$ which was developed and conducted in a strong spirit of collaboration between the Telethon Institute for Child Health Research, peak Indigenous bodies, the Australian Bureau of Statistics and government and community organisations. An Aboriginal steering committee guided its design and implementation, emphasising respectful relations between the study group and the communities surveyed. ${ }^{7}$ There have been advances in other areas of mental health research with the development of properly standardised culturally appropriate screening tools, such as the Kimberley Indigenous Cognitive Assessment for diagnosis of dementia among older Aboriginal and Torres Strait Islander people. ${ }^{8}$

The research described by Jorm and Hunter and their respective colleagues represents a view of mental illness at the visible tip of an iceberg of significant social and health disadvantage. Effective research strategies to encompass the whole "iceberg" are necessarily complex. A landmark study of the variability in suicide rates among Canadian First Nations people in British Columbia is an example of a successful study concept that demonstrated a link between cultural empowerment and positive health outcomes. ${ }^{9}$

Studies into the success or otherwise of funding models to address Indigenous disadvantage would be advantageous. Recent economic initiatives such as the Australian National Partnership Agreement on Indigenous Economic Participation ${ }^{10}$ have attempted to redress Indigenous disadvantage across a broad range of well resourced funding frameworks. This framework appears to take into consideration the prerequisites for health outlined in the 1986 Ottawa Charter for Health Promotion. ${ }^{11}$ The initiatives have also incorporated new thinking about the economic empowerment of human agency to effect change for disadvantaged individuals proposed by Amartya Sen, ${ }^{12}$ who was awarded the Nobel Prize for Economic Science in 1998. Sen's concept of empowerment of human agency is aimed at ensuring that individuals are endowed with "capabilities that allow them the freedom to choose to live their lives in ways that have real meaning and real value". ${ }^{13}$

Elsewhere, I have suggested that these general economic principles could be closely aligned with similar funding strategies that could enable recovery for people affected by severe mental illness. ${ }^{14}$ For example, quality housing is an essential "pillar" of the Australian Indigenous funding agreement. It would also be an essential pillar of any proposed mental health recovery funding framework with the concept of a stable home reinforcing factors of "ontological security", namely, constancy, daily routines, privacy and a secure base for identity construction. ${ }^{15}$

The "recovery model" for people affected by mental illness refers both to the subjective experiences of hope, healing, empowerment and interpersonal support experienced by people with mental illness, their carers and service providers, and to the creation of recovery-oriented services that engender a positive culture of healing and a support for human rights. ${ }^{16}$ It is hoped that a broad vision for recovery for Aboriginal and Torres Strait Islander people affected by mental illness, along with improved research instruments where appropriate, may be a step towards regaining the mental health of a population in which it has been so significantly lost.

Competing interests: No relevant disclosures.

Provenance: Commissioned; externally peer reviewed.

1 Parker R. Australian Aboriginal and Torres Strait Islander mental health: an overview. In: Purdie N, Dudgeon P Walker R, editors. Working together: Aboriginal and Torres Strait islander mental health and wellbeing principles and practice. Canberra: Commonwealth of Australia, 2010.

2 Parker R. Australia's Aboriginal population and mental health. J Nerv Ment Dis 2010; 198: 3-7.

3 Hunter EM, Gynther BD, Anderson CJ, et al. Psychosis in Indigenous populations of Cape York and the Torres Strait. Med J Aust 2012; 196: 133-135.

4 Jorm AF, Bourchier SJ, Cvetkovski S, Stewart G. Mental health of Indigenous Australians: a review of findings from community surveys. Med J Aust 2012; 196: 118-121.

5 Chang D. An introduction to the politics of science, culture, race, ethnicity and the Supplement to the Surgeon-General's Report on Mental Health. Cult Med Psychiatry 2003; 27: 373-383.

6 Hunter E. Mental health. In: Thomson N, editor. The health of Indigenous Australians. Melbourne: Oxford University Press, 2003.

7 Western Australian Aboriginal Child Health Survey. Research themes. 2007. http://www.ichr.uwa.edu.au/waachs/themes (accessed Dec 2011).

8 Smith K, Flicker L, Dwyer A, et al. Factors associated with dementia in Aboriginal Australians. Aust N Z J Psychiatry 2010; 44: 888-893.

9 Chandler MJ, Lalonde C. Cultural continuity as a hedge against suicide in Canada's First Nations. Transcultural Psychiatry 1998; 35: 191-219. doi: 10.1177/ 136346159803500202.

10 Council of Australian Governments. National Partnership Agreement on Indigenous Economic Participation. 2008. http://www.coag.gov.au/intergov_ agreements/federal_financial_relations/docs/national_partnership/national_ partnership_on_indigenous_economic_participation.pdf (accessed Dec 2011).

11 Ottawa Charter for Health Promotion. First International Conference on Health Promotion. Ottawa, 21 November 1986 - WHO/HPR/HEP/95.1. http:// www.who.int/hpr/NPH/docs/ottawa_charter_hp.pdf (accessed Mar 2011).

12 Sen A. Development as freedom. Oxford: Oxford University Press, 1999.

13 Henry K. Addressing extreme disadvantage through investment in capability development. Closing Keynote Address to the Australian Institute of Health and Welfare Conference "Australia's Welfare 2007". Canberra. http:// www.treasury.gov.au/documents/1327/PDF/Health_and_Welfare_ Conference.pdf (accessed Mar 2011).

14 Parker R. A new economic and social paradigm for funding recovery in mental health in the twenty first century. Rijeka, Croatia: InTech, 2011. http:// www.intechopen.com/articles/show/title/a-new-economic-and-socialparadigm-for-funding-recovery-in-mental-health-in-the-twenty-firstcentury (accessed Dec 2011).

15 Padgett $D$. There's no place like (a) home: ontological security among people with serious mental illness in the United States. Soc Sci Med 2007; 64: 19251936.

16 Leff J, Warner R. Social inclusion of people with mental illness. Cambridge: Cambridge University Press, 2006. 